\title{
Author Correction: Select autophagy genes maintain quiescence of tissue-resident macrophages and increase susceptibility to Listeria monocytogenes
}

Ya-Ting Wang (D), Konstantin Zaitsev D, Qun Lu, Shan Li, W. Timothy Schaiff, Ki-Wook Kim, Lindsay Droit, Craig B. Wilen (D, Chandni Desai, Dale R. Balce, Robert C. Orchard D, Anthony Orvedahl, Sunmin Park, Darren Kreamalmeyer, Scott A. Handley, John D. Pfeifer, Megan T. Baldridge (iD, Maxim N. Artyomov, Christina L. Stallings (D) and Herbert W. Virgin (D)

Correction to: Nature Microbiology https://doi.org/10.1038/s41564-019-0633-0, published online 20 January 2020.

In Fig. 3 b of this Letter originally published, in the Csf1r image, the ' 7 ' label was incorrectly placed; it should have been positioned within the empty bordered space adjacent to ' 8 '. This error has now been corrected.

Published online: 25 May 2021

https://doi.org/10.1038/s41564-021-00923-X

๑ The Author(s), under exclusive licence to Springer Nature Limited 2021 